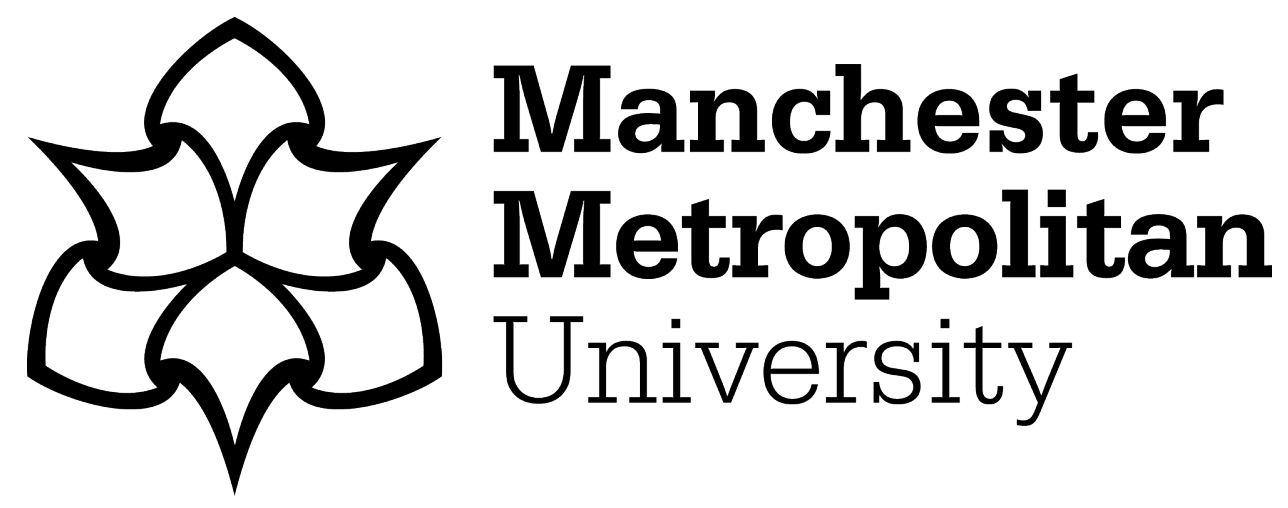

Thompson, G and Sellar, S ORCID logoORCID: https://orcid.org/0000-00022840-5021 (2018) Datafication, testing events and the outside of thought. Learning, Media and Technology, 43 (2). pp. 139-151. ISSN 1743-9884

Downloaded from: https://e-space.mmu.ac.uk/625009/

Version: Accepted Version

Publisher: Taylor \& Francis

DOI: https://doi.org/10.1080/17439884.2018.1444637

Please cite the published version 


\title{
Datafication, testing events and the outside of thought
}

\begin{abstract}
Education is undergoing various transformations due to new data-driven educational technologies and the management of educational data through data infrastructures. These technologies are frequently promoted to parents and the profession as being 'revolutionary' because they represent a new generation of learning. While CATs may arguably improve various efficiencies, the argument that they will revolutionise education requires evaluation. In this paper we draw on the philosophy of Gilles Deleuze and Felix Guattari to theorise (a) the desire for data amongst policymakers and (b) the effects of data infrastructures as systems that coordinate educational thought. We argue that, rather than revolutionising learning as promised, datafication in computer-based modes merely offers more intense expressions of longstanding possibilities for learning. We describe three types of events—breaks, cracks and ruptures—and argue that data-events translate cracks (imperceptible changes that constitute learning) into breaks (information), but either cannot generate rupture (difference) or represent rupture as error. However, the intensification of learning through datafication may, we suggest, rupture educational thought more broadly.
\end{abstract}

Keywords: data, Deleuze, information, technology, educational testing, the outside

... and the skeptics, a species of nomads, despising all settled modes of life, broke up from time to time all civil society.

(Kant, The Critique of Pure Reason, Preface to the First Edition).

\section{Introduction}

Education institutions, and the people who work and learn in them, are constantly generating and using more and more data. Much of this data is in digital form, either in collection, production or analysis. These data are fuelling increasingly complex forms of software, including digital learning environments, computer adaptive tests (CATs) and student information systems. The development of these different platforms has driven the development of interoperability standards in education. Interoperability is an essential feature of data infrastructures that are designed to facilitate the integration and coordination of data across multiple systems, and this integration creates opportunities to employ 'big data' techniques such as predictive analytics, machine learning and education data-mining. For example, the next generation of computerbased standardised testing will generate greater volumes of data, more frequently, and these data are being integrated into emerging data infrastructures (e.g. business intelligence platforms) to add new force, or intensity, to datafication in schooling (Sellar \& Thompson, 2016). However, the conceptual tools that we have for thinking through these new technologies in assessment and learning, particularly in relation to implications for politics, policy and practice, remain caught between dystopian visions of technology undermining human values, culture and subjectivity, or utopian fantasies about continual improvements to the efficiency and effectiveness of learning. 
We are particularly interested in CATs because of the expectation in reports and advertising focusing on educational technology, and among certain actors within education policy contexts, that CATs can solve many of the 'wicked problems' confronting assessment, learners, educators and education systems (Mayer-Schönberger \& Cukier, 2013). For example, in an interview in 2016, Albert Hitchcock, $\mathrm{ClO}$ of the edu-business Pearson, unveiled plans to "create a global digital platform for education" that would "revolutionise the education industry through a flexible, API-driven, cloud-based platform" (Ismail, 2016. Emphasis added). CATs represent an important part of this platform that have become desirable because they promise greater efficiency, precision, timeliness and a more enjoyable and motivating test experience for students (Frey \& Seitz, 2011; Martin \& Lazendic, 2018). CATs are technical objects that represent broader, and deeper, educational and social desires to measure learning and to use quantitative data to inform policy and pedagogical decisions. For example, Australia's national literacy and numeracy testing programme (NAPLAN) has been trialling CAT across selected populations since 2013 (ACARA, 2016). The motivations for establishing this testing regime are complex and multifaceted, rooted in desires for education systems that better manifest economic efficiencies, $21^{\text {st }}$ century skills, improved quality, and greater equity. Increasingly, efforts are being made to develop data infrastructures across which national and international databases link to enable faster and more precise analysis with the aim of eradicating educational underachievement (Thompson, 2017). While many of these developments have been scrutinised by researchers in psychology, sociology and policy studies, the claim that has escaped scrutiny is that digital solutions such as CATs will revolutionise educational assessment and, in turn, educational thought more generally.

Critical scholarship continues to ask questions about the effects of datafication in education (cf. Enyon, 2015), with particular emphasis on: the rise of data surveillance (Roberts-Holmes \& Bradbury, 2016); concerns regarding children's rights (Lupton \& Williamson, 2017); new forms of digital governance (Williamson, 2015); the impact of the technologies on education policy and practice (Roberts-Holmes, 2015); and concern regarding the role of technology companies within education (Reckhow \& Snyder, 2014). While this recent work has adopted what might be called a 'digital sociology' approach (Selwyn, 2015), we will take a different approach here. We consider datafication and its implications for educational thought from a philosophical perspective, drawing on the writings of Gilles Deleuze and Felix Guattari. We pursue Deleuze and Guattari's theoretical approach to this problem for three reasons: first, because claims to revolution, or the creation of new possibilities, are essentially claims to the introduction of difference or the untimely, which are key concerns of Deleuze's philosophy. Second, Deleuze and Guattari offer us conceptual tools for analysing how thought is changing, or undergoing a revolution, as a result of technological advances such as datafication, CATs and machine learning. Third, there is much to be gained through engaging with an almost forgotten line of inquiry in poststructural theory that considers the coordinates of thought and its untimeliness, or its 'outside'.

\section{Deleuze, Guattari and Thought as Untimely}

Deleuze (1994), and Deleuze and Guattari (2005) writing together, argue that revolutions in any social institutions such as education only proceed through challenges to the orthodox or 
representational image of thought, which "determine[s] what it means to think and what the ultimate goals of thought are" (Voss, 2013, p. 13). Revolutions in and of education must alter the orthodox image of educational thinking - the set of implicit presuppositions about what it means to think-and only through this can it create new possibilities for thought that can bring about new activities, behaviours, organisations and connections. Deleuze and Guattari (2005) discuss the problem of thinking the outside, which is a thought that cannot result in achieved knowledge. ${ }^{1}$ This distinction is critically important in educational contexts where 'disruptive innovation' has become a fairly common claim in education policy interventions. With the emergence of new educational technologies such as CATs, we are often promised a revolution in education by certain sections of the education technology community and their supporters in education policy networks, but as Deleuze and Guattari (1994) observed two decades ago, the concepts offered by information and technology companies are just more products for sale, not new tools for thought.

Deleuze and Guattari (1994) argue that thought in its philosophical mode "creates concepts" for the express purpose of extracting "an event from things and beings, to set up the new event from things and beings" (Deleuze \& Guattari, 1994, p. 33). Datafication also has a relation to events, insofar as each programmatic data-machine produces effects through events of different kinds. Theorising the form and function of these events is necessary in order to consider whether the relation between data and thought provides conditions for thinking otherwise: what we will call the thought of the outside. Importantly, we do not claim that thinking the outside is in any way better than educational orthodoxies or that it will lead to an improvement in learning. Rather, we want to hold the desire for data-driven innovation that is expressed in the development and promotion of new infrastructures and technologies up to scrutiny. We argue that there can be nothing revolutionary about CATs, in contrast to desire for the outside.

We begin by introducing the theoretical framework of the paper. A brief discussion of data and information is then undertaken, with the aim of illustrating how thought that is formed in digital learning environments such as CATs ultimately conforms to a model: an information ontology (Sellar \& Thompson 2016). This is followed by an overview of standardised testing and an argument for why the information that it generates reinforces the orthodox image of educational thought. Drawing from Deleuze and Guattari, we then develop a typology of data events to argue that CATs, and standardised testing in general, cannot produce events that expose thought to the outside.

\section{Datafication and information}

Large-scale testing is an obvious example where a new and efficient data assemblage has been

${ }^{1}$ Deleuze and Guattari's reference to the thought of the outside echoes a longer engagement with this idea by thinkers such as Georges Bataille, Maurice Blanchot, Michel Foucault and Pierre Klossowski. Blanchot's writings are particularly influential in this regard, and his concept of the outside can be defined as: 'a power that wants to be a power even in the region of the ungraspable, where the domain of goals ends' (Blanchot, 1982, p.106). Deleuze (1994) makes reference to 'that point of which Maurice Blanchot speaks endlessly: that blind, acephalic, aphasic and aleatory original point which designates 'the impossibility of thinking that is thought', that point at which 'powerlessness' is transmuted into power, that point which develops in the work in the form of a problem' (p. 199). 
constructed over time and shapes how school systems operate (Lingard \& Sellar, 2013), how pedagogical decisions are made (Lingard, Thompson, \& Sellar, 2015), how teaching is evaluated (Ball, 2003) and how learning is defined (Biesta, 2010). These testing assemblages utilise increased computational and digital power in various ways such as the incorporation of test data into broader platforms and learning systems. The selling point remains that we are on the cusp of a data revolution in education, whereby "inferred student data" produced through online, normed assessments such as CATs will:

impact education in a big way. It is inevitable. It has already begun. If you're part of an education organization, you need to have a vision for how you will take advantage of big data. Wait too long and you'll wake up to find that your competitors (and the instructors that use them) have left you behind with new capabilities and insights that seem almost magical. (Ferreira, 2013)

This claim to the 'almost magical' revolution begs the question as to how we might define what constitutes revolution in educational contexts. Furthermore, understanding the desire for 'revolution' through datafication in education requires analysis of the types of events produced by testing, which is now a key site of data production in schooling. We argue that the production of more and more data through digitised, integrated and adaptive forms of testing is unable to produce a new image of thought that could sufficiently disrupt the current orthodoxy. Thought is not so easily tricked by fashion and word-play. As we shall demonstrate, standardised testing, both in its design and application, and the subsequent advocacy/opposition divide, is produced within a dogmatic or orthodox image of thought and thus limits the conditions for thinking about learning, which is also a matter of learning to think.

Data have always been produced in schooling, from attendance records and inspection reports to matriculation results and standardised testing at national and international scales. As Selwyn (2015, p. 65) argues, digital data can be produced from a variety of sources including deliberate production (e.g. standardised assessments, student information systems) or volunteered through the use of digital technologies and more covert forms of monitoring and surveillance. Technological innovation and development has meant that public systems like education are increasingly "the target for a host of governmental interventions and reforms augmented by software" (Williamson, 2015, p. 84). Williamson (2015, p.84) suggests that in English school systems a new form of digital governance is emerging that uses "network-based communication and database-driven analytics software" that mediates educational conduct and promotes new organisations into privileged positions within these systems. The software driving these interventions have rarely been interrogated and our focus in this paper is on the production of the data upon which these programs operate and from which they inherit particular limitations.

It is necessary to begin by distinguishing between data and information. Following Rosenberg (2013; Rosenberg, 2013) and Galloway (2011), we define data as 'givens' or, more specifically, what is given for argument. Data are not necessarily numerical, although the term now commonly refers to numerical data in digital form. Rosenberg (2013) argues that, during the $18^{\text {th }}$ century, there was a shift in how the term was understood, from what is given in principle or through revelation to what is given through experience or experiment. Moreover, Rosenberg 
distinguishes data from facts and evidence, arguing that the latter emerge from meaning-making processes.

Data has no truth. Even today, when we speak of data, we make no assumptions at all about veracity. Electronic data, like the data of the early modern period, is given. It may be that the data we collect and transmit has no relation to truth or reality whatsoever beyond the reality that data helps us to construct. (2013, p. 37)

Data are the givens from which sense is made, rather than having inherent meaning or truth. This distinction is clearly illustrated by Rosenberg's suggestion that false data are still data, whereas a false fact ceases to be fact.

Importantly, what is given is not 'raw', because "to enter into presence means to enter into form" (Galloway, 2011, p. 77). Data enter into form as information. Another way to frame this is to argue that "data are characterized as phenomena in the universal domain, and knowledge is characterized as phenomena in the subjective domain" (Zins, 2007, p. 488). Knowledge is dependent upon the form that models or organises the data. As Derrida (1983, p.14) writes, '[i]nformation does not inform merely by delivering information content, it gives form'. It is thus impossible to separate data from information in actuality, but distinguishing between the two concepts draws attention to the process of formation. The context in which data is given has important effects on its formation and these contexts are changed by computer-based processes that both radically increase the volume of information captured and give it form according to models determined by the architecture of both software and hardware (Kittler, 1992). This aligns with the General Definition of Information (GDI), which "has become an operational standard" in fields such as Information Science and Information Systems Theory (Floridi, 2004, p. 42). The GDI is "semantic content in terms of data + meaning".

The etymology of the term information is instructive when thinking about how information, understood according to the General Definition, enters into discursive form within educational contexts. In its earliest usages, information can be understood as (a) a synonym for education (the idea that to educate and to inform are the same activities) and (b) as the moral or religious training of the body and the soul. From these early usages we can see how information connotes a sense of purpose, or rendering data fit-for-purpose, always within a pre-existing schema. If we think about testing as an example, the desire for testing is a desire for organisation (think here of the spiritual sense of monastic organisation).

We have previously argued that CAT necessarily limits learning to the model that facilitates the production of information from test data (Sellar \& Thompson, 2016). Information ontologies are used to model a world for the operations of computer code and to enable interoperability between systems. Here we want to extend this argument to an inquiry into why people desire the organisation and limitation produced by datafication. When Ball (2003) wrote about the terrors of performativity in schooling, which can be understood as an effect of specific kind of datafication, he identified a problem at the level of the subject that still requires examination: how is the desire for data produced? 
Floridi (2010, p. 8) argues that the information revolution, which he dates to the middle of the $20^{\text {th }}$ century, shifts not only our "understanding of the world and of our interactions with it, but also in our self-assessment and identity". The desire for data emerges with a shift in the centrality of information and information systems in contemporary life. For Deleuze, desire is not a property of a pre-existing subject ('my desire'), but produces subjectivities. New subjective desires arise with changes in the production of desire (Holland, 2005). As Buchanan (2014, p. 11) reminds us, Deleuze and Guattari argue that what 'exists' needs to be accounted for affirmatively as a product of desire. Using Nazism as their example, Deleuze and Guattari (1983, p. 29) write that the German "masses were not innocent dupes; at a certain point, under a certain set of conditions, they wanted fascism, and it is this perversion of desire of the masses that needs to be accounted for". From this perspective, datafication in education must exist because it is desired. This, of course, is not to be mistaken as an endorsement of the desired object. Rather, what is produced or desired is a form of social production, because "if something exists, it exists because it is desired; if a state of affairs exists, it exists because it is desired; if a certain behaviour exists, it exists because it is desired" and so on (Buchanan, 2014, p. 11). The analytical work to be done, then, is to consider where the desire for datafication in education, for a data-driven 'revolution' in education, might lead.

The desire for data produces the "actuality of the objects of those representations" (Kant, 1911, p. 16). Data and its educational forms (tests, visualisations and rankings, to name a few) based on those data are in effect manifestations of a particular desires. The need for data expressed by many teachers, principals and education systems is a powerful dimension of this new subjectivity. Groups and individuals come to believe that they need something to solve their problems and this lack is felt as a lack of data. "Desire is not bolstered by needs, but rather the contrary; needs are derived from desire: they are counterproducts within the real that desire produces" (Deleuze \& Guattari, 1983, p. 27). Desiring-production and social production "are identical in nature, but always operate under different regimes" (Holland, 2005, p. 55). To understand desire we have to determine "the essence or nature of desire, no longer in relation to objects, aims or even sources (territories) but as an abstract subjective essence" (Deleuze \& Guattari, 1983, p. 270). So the question is: what is the abstract essence of this desire?

This need for data derives from a very particular concern to know, or to be certain, in order to manage education in risky modernity. This 'bargain with modernity', as Giddens (1990) names it, creates a social desire in individuals to be or become operational or commensurable as a marker of their trust. For Lyotard (1984), 'operational' and 'commensurable' are significant terms that derive from computer-based knowledge systems that he felt would increasingly ground epistemology. Commensurability is particularly important as it encompasses the transformation of qualities to quantities (measurement), which standardises the meaning derived from data (interoperability). As Lyotard (1984, p. 4) argues, with computerisation

the nature of knowledge cannot survive unchanged ... [it can] become operational, only if learning is translated into quantities of information. We can predict that anything in the constituted body of knowledge that is not translatable in this way will be abandoned and that the direction of new research will be dictated by the possibility of its eventual results being translatable into computer language. 
The desire to be operational requires the production of, and belief in, data, grounded as it is by a knowledge system based on computation. For Lyotard, as this desire for computational data grows, the desirability of other forms of knowledge and lines of research diminishes. What cannot be computed is forced to disappear and "the legitimation of that power is based on its optimizing the systems performance ... be operational (that is, commensurable) or disappear" (Lyotard, 1984, p. xxiv).

One interesting aspect of the desire for knowledge in this form is that it has a positive feedback effect, always producing the need for more and better information. It is this 'coming to information' that seems particularly evocative. Why is it that this sense is made of data in schools rather than "other possibilities... such as the teacher who becomes indifferent to the database, who neither tries to ignore the changing expectations of the teacher nor manipulate the data by saying; 'So, you've created some data-points. So what!' (Thompson \& Cook, 2014, p. 140). To analyse the desire for operability we need to discuss standardised testing in more detail, including its relation to the orthodox image of educational thought.

\section{Standardised testing and the orthodox image of thought}

Standardised testing has been driven by a view that better data necessarily creates the conditions for social progress and thus technical expertise ought to be devoted to this task. Standardised tests are administered "uniformly" to a large number of students and "scored in a predetermined manner" (Popham, 2001, p. 39). There are two types of standardised tests: sample tests - where a representative sample of students sit the test-and census tests-where all students within the designated population sit the test. Those who are critical of standardised testing rarely pay sufficient attention to the creation of these tests, while those who support the tests rarely pay sufficient attention to their potential misuse and perverse consequences (Sellar, Thompson, \& Rutkowski, 2017). One problematic line of argument found in much academic literature is that standardised tests are inherently an instrument of neoliberal education policy, ignoring of course that standardised testing pre-exists neoliberalism by many decades.

A test is an arrangement of material to be tested that occurs in three distinct stages. The first stage is the domain. The domain is the specific area of interest that is being measured, whether it is a body of knowledge, skills, abilities or attributes. Essentially, domains constitute the sum of knowledge of a particular field that has sedimented over time. Domains are made up of subdomains that have a specific relationship to each other. It is important to note that most tests are developed to report on "more abstract traits called constructs" (Madaus, Russell, \& Higgins, 2009 , p. 40). A construct is (usually) the statistical creation of a theoretical idea that is not directly observable, but is assumed to have observable behaviours that can be measured. Examples include intelligence, self-esteem, engagement, literacy, numeracy and so on. Ultimately, observable behaviours (such as answering questions correctly) become proxies that are used to infer the relative attainment of these constructs-what is ultimately measured is test performance (Dohn 2007).

Standardised testing captures what can quantified and it is impossible for any test to measure a domain completely in the time allocated for test administration. Thus, the second stage is that of 
sampling - all standardised tests are effectively samples of domains and sub-domains. A test of 40 to 50 questions is sampled in such a way that a meaningful prediction can be made of attainment within the domain of interest. The sample of items is guided by a test specification plan, which includes the number of items in the test, which sub-domains will be included, the proportion of items in each sub-domain, and the specific characteristics of individual items such as their difficulty and question style (Madaus, Russell, \& Higgins, 2009, p. 41).

The third stage is that of inference, or how test scores can be used to infer achievement within the domain. In other words, "domain performance, not test performance, is really the interest in any testing situation" (Madaus, Russell, \& Higgins, 2009, p. 47). This can occur at the level of the individual (for example, how well a Year 4 student understands arithmetic) or can be aggregated into larger groups to enable comparisons between classes, schools, systems and nations. While inferences from tests appear to be almost limitless, and apparently easy to make, the real question is how to make valid inferences. This is notoriously difficult (Newton \& Shaw, 2014). Ultimately, "test performance on a sample of items drawn from the domain is used to make an inference about a student's or a group's performance relative to either the domain or to an entirely different domain of interest" (Maduas, Russell \& Higgins, 2009, pp.49-50).

Recent technical and computational developments require the addition of another stage to this schematic. With test developers no doubt stung by frequent criticism of tests being 'snapshots' that fail to capture learning, and driven by the desire to make tests better, new forms of standardised testing such as CATs are being used in school systems. CATs apply "prediction methodologies to reduce the length of the test without sacrificing accuracy" (Hwang, 2003, p. 218). While traditional pen and pencil standardised tests provide the same schedule of questions to students, often moving from easier to more difficult questions, CATs "adapt to a student's ability level" through offering branches or pathways (Shapiro \& Gebhardt, 2012, p. 296). These are known as testlets. At each stage of standardised testing there is selection.

While standardised assessments have not generated data with the volume, variety or velocity characteristic of big data, CATs promise to capture greater volumes of data (e.g. log file data) in real-time and they dramatically reduce the time between data generation, analysis and action. For example, CATs add an extra dimension to selection, beyond domain samples and inferences, which cuts across each of the preceding stages. What distinguishes CATs from paper and pencil tests is that selection, previously understood as a force applied externally to the test, is now internalised within the activity of test-taking itself. While students have always selected answers to questions, external agents choose the design of the tests (domains, subdomains, items) and how to represent the tests (cut-off scores that indicate bands, levels or grades). However, selection in CATs also occurs during the tests because, at predetermined points, students are streamed or branched into different 'testlets' based on attainment in preceding questions. These selections are made by algorithms embedded in the tests.

Each act of selection is an event. These events range from the selection of the items in the domain to the selection of the student who answers the questions and from the teacher who uses the data to make decisions about curriculum and pedagogy to the policymaker who makes decisions about the effectiveness of educational provision and directions for education reform. 
The test cycle is a collection of selection events, but the question remains: What kinds of events are these? And how do these events capture people's attention and desire? Our answer, which the rest of the paper develops, is that testing produces desire for data because it promises both operability and optimisation.

We are promised that new technologies such as CAT will revolutionise learning, but so often the intensification of standardised testing and its computerization close thought in upon itself. No doubt this is one form of the social production of what is desired: while some claim that testing will 'revolutionise' education, in most cases it simply represents an optimised version of the image of education that we already have. We suggest that there remain other (either troubling or invigorating, depending upon your orientation) possibilities for thought, as a result of the development of new kinds of human-machine relations that we can begin to articulate using Deleuze's concept of the event.

\section{Thought, events and testing}

So what kind of events does the production of data through testing generate? An event is an occurrence, something that happens. But clearly everything that happens does not qualify as an event; this term is generally reserved for remarkable occurrences that stand out from the background of everything that happens. For Deleuze, the event is a decisive technical term that needs to be carefully understood. Events are turning points, singularities: 'bottlenecks, knots, foyers and centres; points of fusion, condensation and boiling; points of tears and joy, sickness and health, hope and anxiety, "sensitive" points' (Deleuze, 1990, p. 52). Sense is an event and so we might also ask: What sense is made of testing? In asking this question we extract the problem of the testing event from the presuppositions of the tests themselves.

In a discussion of the novella, Deleuze and Guattari (2005) outline three kinds of events: breaks, cracks and ruptures. Breaks and cracks are of a different quality to rupture events, "which [are] like a line of rupture or a 'clean break' and [mark] the exploding of the other two, their shake-up" (Deleuze \& Guattari 2005, p. 199). To understand what happened, what is happening, or whether anything happened is the sense of the event. In Table 1 we associate these three events with different concepts, processes and expressions that demarcate the territory, and possibility, of sense-events in education. We then outline each type of event and discuss how it is or is not manifest in standardised testing, and particularly CATs.

Table 1: Three kinds of event

\begin{tabular}{|l|l|l|l|}
\hline Event & Concept & Process & Expression \\
\hline Break & Actual & Recognition & Information \\
\hline Crack & Virtual & Learning & Signs \\
\hline Rupture & Line of flight & Difference & Thought \\
\hline
\end{tabular}

Break-events 
The multitude of selections involved in any form of standardised testing are break-events. The break is an occurrence of change from one structural position or identity to another. It occurs within a logic of representation and the change produced is always communicable and predictable. Quoting F. Scott Fitzgerald, Deleuze and Guattari (2005, p. 198) describe such events as proceeding 'by oversignificant breaks, moving us from one term to the other according to successive binary "choices"'. Testing is premised on events of the break type that allocate test takers into limited sets of pre-existing categories (recognition) and, with CATs, this entails a form of 'machinic enslavement' (Lazzarato, 2014) that partially disassembles the subject into human-machine processes (information). Break-events overcode and segment by allocating particular categories and qualities to bodies: "Even when change runs in the other direction, there is nothing to compensate for the rigidification, the aging that overcodes everything that occurs" (Deleuze \& Guattari, 2005, p.198). Break-events are thus macropolitical events, but as Deleuze and Guattari (2005) emphasise, these events communicate with micropolitical events: 'every politics is simultaneously a macropolitics and micropolitics' (p. 213). Break-events thus communicate with crack-events, which occur in the domain of the micropolitical.

Consider an example. The determination of a student as 'passing' or 'failing' is an event that involves a 'choice' that occurs as an incorporeal transformation: the determination of pass or fail changes the capacities of the student who is assessed (e.g. the student may no longer be able to access a particular educational or vocational pathway). This event inheres in language, is actualised in the depths of the body and reworks its capacities. Break-events are actual; that is, they represent potentiality in concrete forms. Individual scores, rankings and judgements about achievement and/or ability express changes in position or perceived identity. Labelling a student as above-average, a school as failing, or a system as excellent based on aggregated data, are all examples of break-events that express potentiality as information. This process is one of recognition: the break-event is (supposedly) the recognition of the capacities and attributes of a given body, but this recognition also changes the perception of that body. Thus, an excellent school may have always conducted itself the same way, with the same effects, but it may require the ranking of 'excellent' based on recognition of testing data (or other data) for the transformation to occur. Of course, these events are limited in that they merely confirm the image of thought that is presupposed in education.

\section{Crack-events}

The crack-event involves more imperceptible forms of change. Instead of blows from the outside-seismic shifts that change the qualities or emergent properties of things in noticeable ways - these events involve "micro-cracks, as in a dish; they are much more subtle and supple, and occur when things are going well on the other side" (Deleuze \& Guattari, 2005, p.198). The self is constituted through multiple crack-events that are only recognised as change after the event (e.g. learning as expressed in the surprise of a new perspective on the world), and this recognition necessarily fails to account for the multiplicity of forces that constituted, nourished and sustained the crack. The crack-event is of a different order to the break-event because it does not contain the conditions of recognition. We argue that learning can be understood as proceeding via crack-events because it is a process of virtual transformation that may or may 
not be incarnated in the depths of the body: "it is so difficult to say how someone learns" (Deleuze, 1994, p. 23). Learning proceeds initially on the surface, through crack-events that "conjugate the distinctive points of our bodies with the singular points of the Objective Idea in order to form a problematic field" (Deleuze, 1994, p. 165). Consider, for example, the way in which the body must conjugate with the forces or signs present in a body of water as it learns to swim (Bogue, 2004).

The crack-event involves a micropolitics of subjectivity, because it occurs when

you reach a degree, a quantum, an intensity beyond which you cannot go ... But what exactly happened? In truth, nothing assignable or perceptible: molecular changes, redistributions of desire such that when something occurs, the self that awaited it is already dead, or the one that would await it has not yet arrived.

(Deleuze \& Guattari, 2005, pp.198-199)

Deleuze and Guattari argue that there is a limit-point to the crack-event, a point at which if the line of travel continues something New can emerge. When cracks become ruptures, thought is produced by a different process of desire. At this limit point, learning can become recognisable (the crack becomes a break) or thought itself can become radically disoriented (rupture). For Deleuze (1994, p. 165), the latter is the condition for true learning: 'we never know in advance how someone will learn' because learning does not proceed according to a method or model. Learning is a violent paideïa and truly creative thought emerges from 'the destruction of an image of thought which presupposes itself and the genesis of the act of thinking in thought itself' (Deleuze 1994, p. 139).

Importantly, crack- and break-events presuppose each other. Crack-events are imperceptible changes that occur continually in schools (such as feelings of bewilderment, anxiety or elation when sitting a test) that produce, to some extent, the self as a process rather than an identity. Break-events produced by testing overcode these molecular changes and incarnate them as durable attributions of performance (the high performing student or school). Break events realise the desire for data in achieved knowledge that produces a sense of certainty. Thus, testing events may produce learning through which a learner struggles, and emerges anew, but these will only become evident after the fact, if at all. Digital technology that enables crack events to be better coordinated, more quickly processed and more insightfully arranged as personalisation hardly seems the stuff of revolution at the level of thought.

\section{Rupture-events}

Rupture-events involve change along "a third line, which is like a line of rupture or a "clean break" and marks the exploding of the other two, their shake-up ... in favor of something else?" (p.199). The 'something else' that occurs in rupture is radical passivity: 'Nothing can happen, or can have happened, any longer' (p. 199). Rupture-events involve absolute deterritorialization (line of flight): "a type of movement qualitatively different from the relative movement" (p. 509) of reterritorialization through breaks and deterrritorialization through cracks. Rupture involves an encounter with the outside, with 'the impossibility of thinking that is thought' (Deleuze 1994, p.199). In rupture, thought searches blindly for new coordinates and we are forced to think in 
absence of a model and without orientation towards an end. The active desire for data can be understood as desire for information that gives coordinates to thought. This desire is frustrated in rupture-events and potentially becomes transmuted into a problematic thought that wrestles with what cannot be grasped as knowledge (difference).

As absolute deterritorialization, rupture involves the creation of a 'new earth'. If breaks are incarnated in the body and cracks stay at the surface, then rupture is about the constitution of a new terrain: "My territories are out of grasp, not because they are imaginary, but the opposite: because I am in the process of drawing them" (Deleuze and Guattari, 2005, p.199). Deleuze and Guattari (2005) write that 'Fitzgerald contrasts rupture with structural pseudobreaks in socalled signifying chains. But he also distinguishes it from more supple, subterranean links or stems of the "voyage" type, or even from molecular conveyances' (p.199). In contrast to molar breaks and molecular cracks, rupture produces new lines of thought and are the only events which can be legitimately characterised, from Deleuze's point of view, as 'revolutionary' in the sense of producing new thought. If any test, or form of datafication, is to be revolutionary, it must produce rupture-events. The claim implied by many promoters iof CATs and other forms of digital, integrative assessment is that they create the conditions for rupture-events. However, as it currently stands, these tests proceed along the familiar line of educational thought, whereby information is assembled, students are tested, data is aggregated, ranking follows along with the subsequent material effects of these rankings. There is nothing new here and thought looks unlikely to be ruffled by this aspect of a digital 'revolution' in education.

\section{Conclusion}

In this paper, we have argued that 'next generation' CATs, data-driven learning environments and algorithmic personalisation are promoted as rupturing with what has come before. Drawing from Deleuze and Guattari, we have sought to describe three types of event: breaks, cracks and ruptures. This typology of events provides us with a way of thinking about learning and its limits. We argue that standardised testing generates break-events when it reorganises thinking about learning on the basis of new information, new comparisons and new predictions. But testing cannot disrupt the orthodox image of educational thought or produyce learning in Deleuze's mor radical sense. Testing may generate breaks and cracks, but it is unable to produce rupture.

Every standardised test is essentially the Same. This statement seems obvious; after all, standardised tests are designed to be the same. However, what we mean by 'Same' is somewhat different to the common usage of this term. The claim is that all tests are created according to an image of thought that limits (a) what tests should be and (b) what the purposes of schooling are (as this necessarily influences how tests are conceptualised, created and administered). The desire for operability that manifests as a need for data is oriented toward conformity with a model rather than creative differentiation. Testing can only repeat the Same: it can only ever produce structural pseudo-breaks.

Testing is an artefact of the selections made throughout the test cycle, which themselves are produced within the socialised world of education. Domains, sub-domains, constructs, specification plans and branching are all conceptualised, constructed and put to work according 
to an image of educational thought. Standardised testing assumes that acts of recognition are precisely what ought to be measured as the desired outcome of education. Educational thought based on the information generated by testing is thus inherently limited to the recognition of correct answers and a simple concept of error. Standardised tests cannot break with the past, therefore no test can deliver on the promise of a revolutionary educational future. CATs automate and intensify this representation, acting as a catalyst in the feedback loop between cracks and breaks.

We concede that rupture-events may occur while a student is engaged in a CAT, but they may also occur in any other situation. As Deleuze argues, we cannot say when or how such events will provoke thought. But, the occurrence of a rupture-event during testing is incidental to the form and function of the test, and CATs, by intensifying the desire for breaks, help to reduce the conditions in which ruptures can occur. Why is it a problem if educational thought is not exposed to rupture?

Following Deleuze, we have defined rupture as an event in which the desire that produces thought is transmuted through an encounter with the outside. The rupture event does not open thought to a different way of learning (understood as recognition and the achievement of knowledge); instead, it constitutes a different movement of thought, one that is no longer relative. Rupture-events invert the relationship between thought and learning and thus are better categorised as learning to think. This is a process without defined end or any certainties that provide a sure guide for thought. Our argument is not that rupture offers a 'better' type of learning, but rather that it constitutes different possibilities for thought. Such possibilities have a much more substantive claim to the 'new' or 'revolution' than hyped developments at the intersection of educational testing and technology.

While speculating about the future is a risky business, we do think that CATs, particularly with their integration into data-driven environments that are designed to optimize pedagogy and assessment, may have 'revolutionary' consequences, but of a different sort than is generally promised. The optimization of learning through algorithms is just one element in a much broader and rapidly intensifying trend toward the automation of cognition as machine learning. As machines increasingly provide cognitive augmentation to thought, what it means 'to think' will become parasitic upon a much more powerful yet narrow model of cognition. A new image of thought may not be human at all. Perhaps the revolution that CATs will contribute to, as part of the broader computerisation of education, will be one in which the potential for thought to be confronted by the outside, in an attitude of radical passivity, is diminished in favour of more active colonisation by an inhuman logic of information processing.

Ultimately, the desire for data that drives the production of CATs and related technologies is a desire that puts pressure on orthodox image of educational thought. The philosopher Nick Land, who drew on Deleuze and Guattari's concepts to think speculatively about techno-capitalist dynamics, observes that '[t]raditional schemas which oppose technics to nature ... are all dominated by a phobic resistance to the sidelining of human intelligence by the coming techno sapiens' (Land 2011, p. 294). Educational thought is clearly structured by this resistance, this could break down as thought becomes integrated with information processing. When human 
thought becomes parasitic on inhuman cognition there is no longer a 'dialectic between social and technical relations, but only a machinism that dissolves society into the machines' (Land 2011 , p. 294). This would be rupture and revolution of a very different kind.

\section{References}

ACARA. (2016). Tailored Tests. Retrieved July 1st, 2017, from National Assessment Program (NAP): https://www.nap.edu.au/online-assessment/research-and-development/tailoredtests

Ball, S. (2003). The teacher's soul and the terrors of performativity. Journal of education policy, 18(2), 215-228.

Biesta, G. (2010). Good Education in an Age of Measurement: Ethics, Politics, Democracy. Paradigm Publishers.

Bogue, R. (2004). Search, Swim and See: Deleuze's apprenticeship in signs and pedagogy of images. Educational Philosophy and Theory, 36(3), 327-342.

Buchanan, I. (2014). Schizoanalysis and the Pedagogy of the Oppressed. In M. Carlin, \& J. Wallin, Deleuze and Guattari, Politics and Education: For a People-Yet-to-Come (pp. 114). New York: Bloomsbury.

Deleuze, G. (1990). The logic of sense. New York: Columbia University Press.

Deleuze, G. (1994). Difference and Repetition. New York: Columbia University Press.

Deleuze, G., \& Guattari, F. (1983). Anti-Oedipus: Capitalism and Schizophrenia. Minneapolis: University of Minnesota Press.

Deleuze, G., \& Guattari, F. (1994). What is Philosophy? New York: Columbia University Press.

Deleuze, G., \& Guattari, F. (2005). A Thousand Plateaus: Capitalism and Schizophrenia. Minneapolis: The University of Minnesota Press.

Enyon, R. (2015). The quantified self for learning: critical questions for education. Learning, Media and Technology , 40(4), 407-411.

Ferreira, J. (2013, July 18th). Big Data in Education: The 5 Types That Matter. Retrieved January 15th, 2018, from The Knewton Blog: https://mktg.knewton.com/resources/blog/knewton/from-jose/big-data-in-education/

Floridi, L. (2004). Information. In L. Floridi, The Blackwell guide to the philosophy of computing and information (pp. 40-61). Oxford: Blackwell Publishing.

Floridi, L. (2010). Information: A very short introduction. Oxford: Oxford University Press.

Frey, A., \& Seitz, N. (2011). Hypothetical use of multidimensional adaptive testing for the assessment of student achievement in the programme for international student assessment. Educational and Psychological Measurement, 71(3), 503-522.

Galloway, A. (2011). Are some things unrepresentable? Theory, Culture \& Society, 28(7-8), 85102.

Giddens, A. (1990). The consequences of modernity. Cambridge: Polity Press.

Holland, E. (2005). Desire. In C. Stivale, Gilles Deleuze: Key concepts. (pp. 53-62). Montreal: McGill Queen's University Press.

Hwang, G. (2003). A conceptual map model for developing intelligent tutoring systems. Computers \& Education, 40, 217-235. 
Ismail, N. (2016, October 17th). Pearson's learning platform set to transform the education industry. Retrieved January 18th, 2017, from Information Age: http://www.informationage.com/pearsons-learning-platform-123462720/

Kant, I. (1911). The Critique of Judgement . Oxford: Clarendon Press.

Kittler, F. (1992). Discourse Networks 1800/1900. Stanford University Press.

Lingard, B., \& Sellar, S. (2013). Catalyst data': perverse systemic effects of audit and accountability in Australian schooling. Journal of Education Policy, 28(5), 634-656.

Lingard, B., Thompson, G., \& Sellar, S. (2015). National testing in schools: An Australian assessment. London: Routledge.

Lupton, D., \& Williamson, B. (2017). The datafied child: The dataveillance of children and implications for their rights. New Media \& Society, 1461444816686328. New Media \& Society, 19(5), 780-794.

Lyotard, J. (1984). The postmodern condition: A report on knowledge . Minneapolis: University of Minnesota Press.

Madaus, G., Russell, M., \& Higgins, J. (2009). The Paradoxes of High Stakes Testing: How they affect students, their parents, teachers, principals, schools. and society. Charlotte, NC:: Information Age Publishing.

Martin, A., \& Lazendic, G. (2018). Computer-Adaptive Testing: Implications for Students' Achievement, Motivation, Engagement, and Subjective Test Experience. Journal of educational psychology, 110(1), 27-45.

Newton, P., \& Shaw, S. (2014). Validity in educational and psychological assessment. Los Angeles: Sage.

Popham, W. (2001). The truth about testing: An educator's call to action. Alexandria, Virginia: Association for Supervision and Curriculum Dvelopment.

Reckhow, S., \& Snyder, J. (2014). The expanding role of philanthropy in education politics. Educational Researcher, 43(4), 186-195.

Roberts-Holmes, G. (2015). The 'datafication'of early years pedagogy: 'if the teaching is good, the data should be good and if there's bad teaching, there is bad data'. . Journal of Education Policy, 30(3), 302-315.

Roberts-Holmes, G., \& Bradbury, A. (2016). Governance, accountability and the datafication of early years education in England. British Educational Research Journal, 42(4), 600-613.

Rosenberg, D. (2013). Data before the fact. In L. Gitelman, "Raw Data" is an oxymoron (pp. 1440). Massachusetts: MIT Press.

Sellar, S., \& Thompson, G. (2016). The Becoming-Statistic: Information Ontologies and Computerized Adaptive Testing in Education. Cultural Studies<-->Critical Methodologies, 16(5), 491-501.

Sellar, S., Thompson, G., \& Rutkowski, D. (2017). The Global Education Race: Taking the Measure of PISA and International Testing. Toronto: Brush Education.

Selwyn, N. (2015). Data entry: Towards the critical study of digital data and education. Learning, Media and Technology, 40(1), 64-82.

Shapiro, E., \& Gebhardt, S. (2012). Comparing computer-adaptive and curriculum-based measurement methods of assessment. School Psychology Review, 41(3), 295-305.

Thompson, G. (2017). Computer adaptive testing, big data and algorithmic approaches to education. British Journal of Sociology of Education, 38(6), 827-840. 
Thompson, G., \& Cook, I. (2014). Manipulating the data: Teaching and NAPLAN in the control society. Discourse: Studies in the Cultural Politics of Education, 35(1), 129-142.

Voss, D. (2013). Deleuze's Rethinking of the Notion of Sense. Deleuze Studies, 7(1), 1-25.

Williamson, B. (2015). Governing software: Networks, databases and algorithmic power in the digital governance of public education. Learning, Media and Technology, 40(1), 83-105.

Zins, C. (2007). Conceptual approaches for defining data, information, and knowledge. Journal of the Association for Information Science and Technology, 58(4), 479-493. 